\title{
GESTÃO ESCOLAR E O ATENDIMENTO DE ALUNOS COM NECESSIDADES EDUCACIONAIS ESPECIAIS (NEE): DA REALIDADE À POSSIBILIDADE DE INCLUSÃO EM UMA ESCOLA PÚBLICA ${ }^{1}$
}

\author{
Zenailde Rodrigues Costa - UEMA ${ }^{2}$ \\ Vanessa Oliveira Almeida - UEMA ${ }^{3}$
}

\section{RESUMO}

Este texto apresenta um recorte do Trabalho de Conclusão do Curso (TCC) de Licenciatura em Pedagogia acerca da atuação gestora na perspectiva da educação escolar inclusiva, por meio de reflexões teóricas abordando aspectos conceituais e legais sobre gestão democrática e participativa no contexto do ensino escolar regular do público alvo da educação especial, bem como conhecimentos teóricos acerca de inclusão escolar, e encaminhamentos de proposta com ações interventivas viáveis para um caminhar rumo a uma gestão escolar inclusiva. A pesquisa teve como objetivo geral, compreender a atuação do gestor escolar diante da inclusão de alunos com NEE em escola pública. E como objetivos específicos, conhecer a relação e convivência entre o gestor e o aluno com NEE, explicar a postura do gestor escolar frente à educação inclusiva nesta escola pública de Timon. Teve como problema da pesquisa "como a equipe gestora atua diante da inclusão de alunos com necessidades educacionais especiais (NEE) nesta realidade escolar". Tratou-se de uma pesquisa qualitativa exploratória com a realização de entrevista semi-estruturada com os três gestores de escolas públicas, e dois pais de alunos com NEE. Com base nas análises dos dados obtidos junto aos pais, estes afirmaram que seus filhos são excluídos das atividades escolares e, consideram a formação dos professores e a atuação da gestão insuficiente para $o$ atendimento às necessidades de pessoas com deficiências. Assim, diante dos resultados desta pesquisa pode-se afirmar que se faz necessário e urgente o investimento na formação continuada para os gestores e docentes da escola para que se busque a superação das dificuldades existentes na instituição para cuidar e ensinar de alunos com deficiências, assim como também um maior acompanhamento aos familiares dos alunos.

Palavras-Chave: Gestão escolar. Educação especial. Inclusão escolar. Necessidade Educacional Especial. Formação Docente

\footnotetext{
${ }^{1}$ Trabalho apresentado no Congresso Brasileiro Ciência e Sociedade (CBCS 2019), promovido pelo Centro Universitário Santo Agostinho, de 03 a 05 de outubro de 2019, em Teresina-PI.

${ }^{2}$ Licenciada em Pedagogia pela Universidade Estadual do Maranhão - UEMA; Pós-graduanda do curso de especialização em Libras pela faculdade FAESPI. E-mail:nahilde.amomissoes@ gmail.com

${ }^{3}$ Licenciada em Pedagogia pela Universidade Estadual do Maranhão - UEMA; Pós-graduanda do curso de especialização em Libras pela faculdade FAESPI.E-mail:vanny123olly@gmail.com
} 


\section{congGiESSO CIENCIAESOCIEDADE

\section{INTRODUÇÃO}

ANAIS CBCS 2019 | 3 a 5 de outubro de 2019 | Centro Universitário Santo Agostinho - Teresina - P

No cenário escolar o gestor da instituição pode ser considerado um dos importantes profissionais capazes de contribuir para o alcance da qualidade da educação, mediante sua gestão na atividade da equipe escolar. Nas últimas décadas, tem sido relacionado a qualidade da gestão escolar com a qualidade de ensino, e isso tem sido recorrente nos resultados obtidos nos sistemas de avaliação externa de alguns sistemas de ensino.

O papel do gestor escolar tem sido um assunto constantemente debatido nos estudos e pesquisas acadêmicas, promovendo diferentes discussões a respeito de como este pode fazer a diferença na obtenção de qualidade do ensino escolar. Estudos realizados por, Luck (2009), Mantoan (2006), Mattos (2010), entre outros, revelam como o papel do gestor é fundamental na melhoria dos resultados, na organização e desenvolvimento da escola.

Ressaltamos que apesar do interesse e das discussões sobre a temática da gestão, é necessário ainda avançar nas pesquisas, nos debates, nas produções acadêmicas e na formação do profissional que exerce a função de gestor escolar, principalmente numa perspectiva inclusiva da gestão. A partir do desafio de pesquisar a respeito da gestão escolar e da qualidade do ensino e aprendizagem, propõe-se, nesta análise de conclusão de curso, ampliar a investigação sobre o papel do gestor escolar e sua relação com a qualidade da educação inclusiva na escola.

Embora a realidade social e educacional excludente e preconceituosa ainda tenha muito que avançar rumo à inclusão social e escolar, mesmo que esteja longe de concretizar os ideais de uma educação para todos, o fundamental é tornar efetiva as políticas existentes para que os mecanismos legais possam concretizar o direito de todas as crianças conviverem e aprenderem juntas em espaços regulares. Nessa perspectiva, o grande desafio é organizar as escolas de forma que esta possa contribuir com o aprendizado de todos os alunos, em especial aos que apresentam necessidades educativas especiais (NEE).

Cabe afirmar que a figura do professor em uma escola que trabalha numa perspectiva de educação inclusiva é de essencial relevância, nesta pesquisa foi ressaltado o trabalho coletivo e de parceria com o gestor escolar frente a esse processo 
ANAIS CBCS 2019 | 3 a 5 de outubro de 2019 | Centro Universitário Santo Agostinho - Teresina - PI

de inclusão. Mesmo porque a educação inclusiva traz à emergência de se prever e prover uma escola que atenda a todos os alunos sem nenhum tipo de discriminação. É imprescindível que haja compromisso de toda comunidade escolar e que ela esteja envolvida, de forma que possa contribuir com a transformação desses espaços educativos.

Tendo em vista a importância da gestão na condução e assessoramento no processo de construção da escola inclusiva, este estudo teve como problema de investigação a seguinte questão: como a equipe gestora atua diante da inclusão de alunos com NEE nessa realidade escolar?

Nosso interesse por esse tema surgiu a partir de nossas vivencias em sala de aula durante dois anos que passamos em períodos de estágio. Diante das situações problemas que foram surgindo ao longo das nossas experiências, surgiram muitos questionamentos de como um diretor deveria proceder com os alunos que apresentavam NEE. Foi possível observar durante nossas práticas em sala de aula que por muitas vezes o diretor escolar ficava alheio a algumas situações, principalmente no que se dizia respeito aos alunos com necessidades educacionais especiais, evidenciando sua pouca participação e contribuição no processo educacional de aprendizagem do aluno.

A importância deste estudo está na compreensão do papel do gestor escolar e suas contribuições diante dos desafios e possibilidades para a efetivação da educação inclusiva ofertada na escola pública. Os resultados da entrevista demonstram o quanto o gestor escolar contribui de forma positiva para que a escola tenha um bom desempenho com os alunos que necessitam de inclusão. Pois um professor que luta por melhorias da escola, que se envolve nas atividades escolares internas e externas, que faz acompanhamento da parte administrativa, pedagógica, democrática e inclusiva, tem maior possibilidade de alcançar indicadores de qualidade.

Este estudo visou também contribuir para que a comunidade escolar amplie conhecimentos voltados para a qualidade da gestão escolar, podendo assim oferecer aos estudiosos desse campo, conhecimentos sobre a temática da gestão e inclusão escolar, uma vez que poderão desenvolver ações que visam contribuir na qualidade do 
ANAIS CBCS 2019 | 3 a 5 de outubro de 2019 | Centro Universitário Santo Agostinho - Teresina - P ensino de sua escola, na formação continuada, na reflexão sobre a própria formação e atuação na área inclusiva, despertando também o interesse em alunos acadêmicos da sua própria área de formação, da pedagogia a áreas afins.

Os objetivos propostos para realização desta pesquisa e, consequentemente, de uma proposição de um projeto de ação interventiva, constituem em instrumentos essenciais para a compreensão e interpretação da temática em estudo. O objetivo geral desta pesquisa buscou compreender a atuação do gestor escolar diante da inclusão de alunos com NEE em escola pública. De modo específico, procurou-se conhecer a relação e convivência entre gestor e o aluno com NEE, explicar a postura do gestor escolar frente a educação inclusiva nesta escola pública de Timon. Teve como problema da pesquisa "como a equipe gestora atua diante da inclusão de alunos com necessidades educacionais especiais (NEE) nesta realidade escolar".

É relevante a observação e participação dos pais quanto à educação e aprendizagem que seus filhos estão sendo inseridos. O gestor às vezes fica abstraio da situação que envolve seus alunos com necessidades educacionais especiais, sendo que os pais por vezes observam como esta inclusão acontece e como de fato seus filhos estão sendo inseridos dentro do ambiente escolar. Quanto à metodologia usada para o desenvolvimento desta pesquisa qualitativa, a análise teve como base uma investigação bibliográfica e de campo. Os sujeitos envolvidos no processo deste estudo foram os gestores de uma escola pública de educação básica do município de Timon-MA e pais de alunos com NEE.

No Brasil, a inclusão-exclusão são duas marcas bem visíveis quando olhamos para a educação no sistema de ensino, tanto público como privado. Para que se ofereça uma educação de qualidade é necessário que os gestores escolares estejam bem atentos, conhecendo legitimamente a lei que vem quebrando as barreiras que se tem erguido diante da educação.

A Lei de $n^{\circ} 9.394$ de 9.394, de 20 de dezembro de 1996, conhecida como Lei de Diretrizes e Base da Educação Nacional (LDBEN), faz referência a educação inclusiva, quando nela diz que (BRASIL, 1988, art. 4으, inc. III): 
ANAIS CBCS 2019 | 3 a 5 de outubro de 2019 | Centro Universitário Santo Agostinho - Teresina - PI

[...] o dever do estado com educação escolar pública será efetivado mediante a garantia de atendimento educacional e especializado gratuito aos educandos com deficiência, transtornos globais do desenvolvimento e altas habilidades ou superdotação, transversal a todos os níveis, etapas e modalidades, preferencialmente na rede regular de ensino.

Seguindo com essa mesma Lei, no capítulo 5, artigo 58, na Lei das Diretrizes e Bases Nacionais (LDBEN) afirma que: "a educação especial, para os efeitos desta Lei, a modalidade de educação escolar oferecida preferencialmente na rede regular, de ensino, para educandos portadores de necessidade especiais".

Ainda no que diz respeito à Educação Especial, o artigo 58, no 10 indício garante que: "haverá, quando necessário, serviços de apoio especializado, na escola regular, para atender as peculiaridades da clientela de educação especial". Nesse artigo da Lei, podemos observar que é dada a devida importância aos alunos portadores de necessidades especiais, respeitando as suas limitações e procurando fazê-lo superar suas limitações, apoio este que até então não fazia parte do sistema de ensino escolar como um todo, apenas em instituições especializadas nesse tipo de atendimento diferenciado.

As pessoas que apresentam necessidades educacionais especiais (NEE) são vistas como indivíduos incapazes, no decorrer da história da educação especial, sendo que em meados do século XIX não havia ainda nenhum projeto de inclusão na sociedade para as pessoas com NEE, que viviam à margem da sociedade. Os descasos eram inúmeros. Considerados inaptos pela sociedade, esses indivíduos eram recusados nas escolas e do convívio social.

No que concerne à educação inclusiva é possível ver inúmeras falhas e violações dos direitos da criança, na prestação de serviços da escola, no descaso do poder público para com os alunos. Apesar de a lei nos garantir um ensino de qualidade a todos, sabemos que não é bem assim que acontece nas escolas, principalmente nas instituições públicas. 
ANAIS CBCS 2019 | 3 a 5 de outubro de 2019 | Centro Universitário Santo Agostinho - Teresina - PI

Uma das maiores dificuldades que as escolas sofrem no que diz respeito à educação inclusiva é saber diferenciar a "inclusão" da "integração". Os dois termos possuem práticas diferentes e muitas escolas ainda não conseguem fazer essa distinção. Além de muitos confundirem a educação inclusiva com a educação especial, é certo que os dois precisam caminhar juntos nesse processo. A escola inclusiva consiste em construir um ambiente escolar capaz de suprir as necessidades dos alunos com NEE, já a educação inclusiva tem o objetivo maior, ensinar o aluno os conteúdos de formas adaptadas e com métodos adequados para o seu melhor desenvolvimento.

Sobre esses aspectos, segundo Mantoan (2003, p.15), fica claro que integrar e incluir "apesar de terem significados semelhantes são integrados para expressar situações de inserção diferentes, se fundamentam em posicionamentos teóricos metodológicos divergentes". O processo de integração dos alunos se dá por meio da sua inserção na sala de aula. As escolas não se preocupam, muitas vezes, com a aprendizagem, para a maioria das instituições inseri-los na sala de aula já é o suficiente. A integração estar voltada para a necessidade que aluno tem de se relacionar com as outras crianças.

Desta forma, é impossível falarmos de educação inclusiva e não incluirmos a gestão democrática como foco principal para que aconteça um desenvolvimento da educação dentro das escolas. Uma escola democrática exige dos seus gestores ações democráticas, pois é através da gestão onde se é possível, de acordo com Mattos (2010, p. 13): “[...] possibilitar a todos os que atuam no cenário educacional uma compreensão mais objetiva acerca das necessidades especiais de seus alunos, a fim de garantir ações e atitudes desprovidas de preconceito".

Cabe considerar que quando a gestão se compromete em ter uma postura democrática e participativa fica mais fácil a inclusão dos alunos, independente da sua necessidade. Além de tudo a escola se compromete também com a sociedade daquele lugar, fazendo com que o processo de inclusão se instale mais rapidamente e com sucesso. No entanto, na prática não é bem isso que acontece. Muitos dos gestores não atuam nas suas escolas de forma democrática, mas sim de forma individualista, uma vez que o poder se concentra nas suas mãos e o mesmo não tem um contato significativo 
ANAIS CBCS 2019 | 3 a 5 de outubro de 2019 | Centro Universitário Santo Agostinho - Teresina - PI

com seus alunos. Às vezes, eles não têm conhecimento das suas necessidades e se não conhecem como poderão tomar as medidas necessária para que esse aluno com NEE tenha o devido acompanhamento?

Quando o gestor escolar se propõe realmente para atuar na escola de forma democrática, ele busca em primeiro lugar conhecer o perfil dos alunos e quais são as suas necessidades. Ele deve estar preocupado com as indigências dos seus alunos, principalmente daqueles que precisam de cuidados especiais. É dele a responsabilidade de ir atrás dos recursos necessários para que a escola tenha a capacidade de acolher todos os alunos, independente de sua necessidade.

Neste sentido, Lück (2009, p. 15) apresenta algumas competências para que a atividade gestora venha desenvolver uma boa gestão, destacamos dentre elas:

[...] uma visão abrangente de escola, um sistema de gestão escolar e uma orientação interativa, mobilizadora dos talentos e competências dos participantes da comunidade escolar, na promoção de educação de qualidade.

A aquisição das competências da atuação gestora torna-se base para que 0 gestor desempenhe com sucesso seu papel. Além de oferecer condições materiais e educativas na edificação de alunos críticos e autônomos. É fato que a competência gestora é demasiadamente necessária para atuação nas escolas, mas o que se percebe é que na escola pública as qualidades dessas competências ainda deixam muito a desejar. É necessário que se invista em novas políticas públicas, que sejam capazes de suprir as necessidades tornando-as mais acessíveis aos alunos com NEE.

\section{ASPECTOS METODOLÓGICOS DE PESQUISA}

De acordo com a realidade da educação básica atual, percebe-se a necessidade de um trabalho mais voltado para a inclusão de crianças com Necessidades Educacionais Especiais (NEE). Para isso, a atuação da equipe escolar tem que conceber para si tal responsabilidade e orientados por uma gestão democrática e inclusiva, haja vista que a 


\section{congGFSSO CIENCIAESOCIEDADE

ANAIS CBCS 2019 | 3 a 5 de outubro de 2019 | Centro Universitário Santo Agostinho - Teresina - P|

gestão tem papel fundamental em uma instituição escolar. Quanto à metodologia utilizada para o desenvolvimento dessa pesquisa optou-se pela abordagem da pesquisa qualitativa, por ter entendimento de que este proporcionaria uma estreita ligação do objeto de estudo com o pesquisador, considerando a compreensão dos sentidos e significados atribuídos à temática da pesquisa por parte dos interlocutores da pesquisa.

Para efetivação desta pesquisa fez-se um levantamento bibliográfico com contribuições teóricas acerca do processo da gestão escolar e da educação numa perspectiva inclusiva. Também foi realizada uma pesquisa de campo em escolas públicas, a entrevista foi usando como instrumento de coleta e análise de conteúdo dos dados obtidos. Partindo do objetivo da pesquisa, foram elaboradas questões para realização da entrevista com um trio gestor e um breve questionário para 2 (dois) pais de alunos que possuem NEE.

Buscou-se coletar dados sobre a gestão participativa e inclusiva da escola para que fosse possível identificar os indicadores que orientassem a análise dos eixos temáticos da pesquisa, e com base nos resultados propor algumas ações concretas que possam ser viáveis para uma proposta pedagógica de intervenção, e assim dar maior contribuição como pesquisadoras.

\section{RESULTADOS E DISCUSSÃO}

No sentido de obter mais informações sobre a atuação da gestão da escola e a inclusão escolar, o posicionamento dos pais de alunos com NEE entrevistados, no que diz respeito ao que consideravam ser uma boa gestão escolar, com enfoque na inclusão escolar, responderam que seria:

Uma gestão que aceite a todos de igual modo. Tanto os que são alunos "normais", ou não. (P1)

Acima de tudo que tenha igualdade. Que trate a todos da mesma maneira, independentemente da situação que ele enfrente para esta na escola. (P2) 
ANAIS CBCS 2019 | 3 a 5 de outubro de 2019 | Centro Universitário Santo Agostinho - Teresina - PI

Segundo as falas dos pais de alunos com necessidades especiais, para que seja

considerada boa uma gestão e inclusiva precisam que atuem de forma que tratem todos os alunos sem distinção. Mesmo diante da especificidade de cada um, que os atendam na escola igualitariamente, e aceite-os sem rótulos ou olhares de estranhamento ou excludente. Sendo indagados sobre a mesma questão os gestores afirmaram que:

Quando o gestor reconhece a importância da participação de todos, tanto na tomada de decisões, orientações, organizações e até mesmo no processo do planejamento. Inclusão é acolher todas as pessoas, sem exceção no sistema de ensino independentemente da cor, raça, de condições física e psicológicas. (G1)

Uma boa gestão escolar é a gente trabalhar em parceria. Acolher esses alunos no caso da inclusão para que ele possa se socializar com as demais crianças, dando todo apoio necessário tanto para as crianças como para as famílias. (G2)

Uma boa gestão escolar é aquela em que todos colaboram uns com os outros. A inclusão para mim é acolher, é receber a criança, é conhecer as necessidades que ela tem, e fazer o possível para que a criança se sinta confortável, que ela possa se desenvolver de acordo com o que lhe é permitido, que ela consiga "caminhar" dentro das suas limitações. (G3)

Segundo estes gestores, podemos observar que foram unânimes ao enfatizarem que uma boa gestão só pode acontecer quando existe a participação de todos nas tomadas de decisões, que é necessário existir parceria em tudo que for desenvolvido para o bom andamento e desempenho escolar, isso envolve o corpo docente como também a comunidade institucional.

Para G1, uma gestão inclusiva é aquela que busca acolher todas as pessoas no sistema de ensino independentemente da cor, raça, de condições físicas e psicológicas. O G2 destaca que ser gestor na perspectiva da inclusão é acolher esses alunos com necessidades educacionais especiais promovendo uma socialização entre eles e as demais crianças, dando todo apoio necessário tanto para as crianças como para as famílias. Para o G3 uma gestão que pretende ser inclusiva requer fazer o possível para 
ANAIS CBCS 2019 | 3 a 5 de outubro de 2019 | Centro Universitário Santo Agostinho - Teresina - PI

que os alunos com necessidades educacionais especiais se sintam confortável, que elas possam ter um desenvolvimento em que consiga "caminhar" dentro das suas limitações.

De acordo com Lopes e Mendes (2006, p. 12), “[...] o gestor deve ser capaz de organizar, relacionar, refletir e analisar a melhor forma de cuidar do setor que ele administra para que consiga êxito no que se propõe a fazer".

A partir do relato dos participantes da pesquisa sobre a questão da inclusão percebeu-se que o foco da equipe gestora está voltado para o acolhimento desses alunos com deficiência, para que de fato aconteça a inclusão e o desenvolvimento desses alunos que necessitam de um olhar diferenciado.

Quanto aos pais, podemos perceber que o desejo deles é de que a inclusão aconteça não só para os seus filhos, mas com os demais alunos que vivem na mesma situação que seus.

A inclusão precisa ser compreendida para além do inserir e integrar alunos com deficiência. Para tanto, torna-se urgente uma quebra de paradigmas excludentes. Todos devem ser incluídos no espaço escolar convivendo com os outros alunos e serem atendidos na sua especificidade. A diversidade humana não pode ser barreira para que os alunos com NEE deixem de alcançar a aprendizagem de qualidade.

\section{CONSIDERAÇÕES FINAIS/CONCLUSÕES}

Esta pesquisa que teve como participantes o trio de gestores da escola e pais de alunos com NEE, e o resultado evidenciou a preocupação à falta de preparo dos professores no que se diz respeito a alunos com NEE, a necessidade de formação educacional voltada a práticas da educação inclusiva, a falta de recursos didáticos que promovam um aprendizado especifico para esses alunos com NEE e de uma melhor infraestrutura na escola para que ocorra a inclusão escolar de fato e de direito e a aprendizagem dos conhecimentos dos alunos com NEE.

Com intuito de responder ao problema de pesquisa apresentado sobre a equipe gestora atua diante da inclusão de alunos com NEE da escolar investigada, cabe afirmar que tanto os professores, quanto a equipe gestora e os pais ainda não estão preparados 
ANAIS CBCS 2019 | 3 a 5 de outubro de 2019 | Centro Universitário Santo Agostinho - Teresina - PI para esse grande desafio social e educacional, sobretudo, no que se refere a inclusão de alunos que demandam atendimento especializado.

A atuação do gestor escolar na perspectiva da inclusiva demanda por uma gestão democrática e participativa ela deve ser incentivadora e mediadora de toda sua equipe, ouvir e orientar os pais dos alunos com NEE, compreender como a escola atende as necessidades educativas dos seus alunos.

Partindo do objetivo desta pesquisa em que se buscou compreender a atuação do gestor escolar diante da inclusão de alunos com NEE em uma escola pública foi possível constatar que a escola pesquisada atende ao que é preceito pelas leis que é o de acolher e integrar alunos no ensino regular. Contudo, é possível observar que a inclusão destes alunos ainda é desfavorável por parte dos gestores e principalmente de alguns professores.

Dentre alguns aspectos que contribuem para que a escola encontre desafios na realização de ações de ensino inclusivo podemos citar a formação insuficiente da equipe escolar na área da educação especial e inclusiva. Os dados revelaram também que o medo e a insegurança, além do desconhecimento do assunto e de práticas para atender esses alunos com NEE, tornam cada vez mais problemáticos os trabalhos da gestão escolar. Vale ressaltar, ao mesmo tempo, o despreparo da própria Secretaria de Educação da cidade e a falta de formação específica para os cuidadores e professores atenderem às necessidades educacionais deste público alvo da educação especial.

Outros problemas pontuais encontrados no âmbito deste estudo foram: a falta de recurso didáticos que atendam e incluam os alunos com NEE nas atividades escolares, a falta de espaço próprio para receber essas crianças por algum momento (durante as horas que estão na escola), que por algum motivo tenham que sair da sala junto com o cuidador.

A partir dos dados da pesquisa e das ações concretas propostas para uma gestão inclusiva requer-se o desenvolvimento de um trabalho colaborativo de todos que fazem a equipe escolar, gestores, professores da escola e pais e ou responsáveis pelos alunos. Assim, com base nos dados desta pesquisa, consideramos que além de reuniões, rodas de conversas e projetos esporádicos e pontuais, torna-se urgente que o trabalho da 


\section{conyghESOO CIENCIAESOCIEDADE

ANAIS CBCS 2019 | 3 a 5 de outubro de 2019 | Centro Universitário Santo Agostinho - Teresina - P| gestão da escola esteja voltado ao desenvolvimento cotidiano e contínuo de ações e propostas e práticas pedagógicas inclusivas, não só para os alunos com NEE, mas para um caminhar coletivo em defesa de uma escola pública inclusiva.

A realização desta pesquisa oportunizou a discussão acerca da gestão participativa e inclusiva destacando a sua importância e necessidade no atendimento de alunos com NEE, para sua permanência e aprendizagem na escola pública, bem como contribuiu para repensar e desenvolver ações interventivas por parte da gestão escolar que possibilitem a sua implementação.

Durante a concretização desta pesquisa, ficou claro que no ambiente escolar, conhecer os alunos com NEE e procurar atendê-lo é importante para que os impactos sejam transformadores da realidade destes alunos. Portanto, pode-se afirmar que a gestão escolar, quando almeja um ensino escolar inclusivo, tem papel importantíssimo na efetivação da inclusão escolar. No processo de transformação dessa instituição, podem fazer com que esses alunos com NEE, bem como seus pais, sintam-se realmente incluídos, contribuindo e participando de atividades escolares por meio de práticas inclusivas, com a finalidade de terem uma vida com melhor qualidade, seja ela social e/ou educacional.

\section{REFERÊNCIAS}

BRASIL. Constituição da República Federativa do Brasil. Brasília: Imprensa Oficial, 1988.

LÜCK, Heloísa. Dimensões da gestão escolar e suas competências. Curitiba: Editora Positivo, 2009.

MANTOAN, Maria Teresa Eglér. Inclusão escolar: O que é? Por quê? Como fazer? 2 ed. São Paulo: Moderna, 2006.

MATTOS, Graciele Fernandes Ferreira. Gestão democrática e inclusão escolar: um possível diálogo. Revista Educação em Foco, Juiz de Fora, sem, p.1-18, 2010. Disponível em: . Acesso em: 10 out. 2018. 